\title{
Management of Regional Corporate Innovation Projects Using Compound Real Options
}

\author{
Sergey Yashin, Nadezhda Yashina, Egor Koshelev* \\ Lobachevsky University, Russia
}

Keywords:

Innovation Project,

Compound Real Option

Received

20 March 2019

Received in revised form

12 May 2019

Accepted

16 August 2019

Correspondence:

ekoshelev@yandex.ru

\section{ABSTRACT}

The purpose of this research is to develop a cost estimation model of a project with its real options. This issue is particularly attributed to the selection of an adequate evaluation model. However, despite the high computational accuracy of a particular model, it can scarcely ever meet the challenge of estimating the cost of compound real options. They may be of two types: 1) options, at the heart of which there are a few basic assets, i.e. projects or project development scenarios; 2) options, at the heart of which there are other options acting as basic assets (options on options). This research presents a model for evaluating compound real options of the first type, i.e. those whose basic assets include various projects and their development scenarios. The technical structure of such compound real options consist in supplementing project evaluation that has been already conducted using the net present value with a number of real options such as an option to scale down a business, an option to abandon a business, an option to develop a business, an option to expand an experience, an option to switch over a business, and an option to delay a project start. 


\section{Introduction}

In the context of the country's high-risky economy, it becomes important to develop and use more advanced technologies to manage corporate financial risks. The classical risk evaluation methods, including calculation of mean-square deviation, risk variation coefficient and even simulation modeling using, among other things, the Monte Carlo method, help only quantify potential risks but do not give any formula to manage them.

On the contrary, the real option technology addresses two challenges at the same time: it quantifies risks and chooses a method to manage them. In such a case, this approach makes it possible use in the business practice not only specific, oftentimes even contrary measures, for risk mitigation but also to produce a broad range of methods to address this challenge, i.e. a set of various real options on the base-case scenario of an innovation or investment project.

Management of corporate innovation projects is a complex multiple-stage process contemplating ample flexibility in decision making by company top managers. Such flexibility is inspired by obtaining new information on future project development outlooks. However, these outlooks should be calculated by financial analysts in advance in order to estimate the effect of a project adequately at the time of its estimation. In this case, we refer to the real option technology allowing for calculation of different alternatives for the development of a project, including its supplement with new projects, which will be available for accomplishment in the event of implementing the best-case or worst-case scenario for the base project (Damodaran, 2002; Limitovsky, 2004; Roche, 2005). In such a manner, the full range of strategic business development outlooks related to a specific innovation project is evaluated.

\section{Literature Review}

Despite a broad coverage of different business lines with real option techniques, this method of financial analysis and strategic planning already boomed as far back as 1990s. At present, many web-sites dedicated to real options, such as www.real-options.com, look like frankly languorous, and only some of them, such as www.realoptions.org, continue conducting serious surveys in this area, but already in a fully scientific field using for this purpose the stochastic financial mathematics instrument with increasing frequency.

In its issue dated August 14, 1999, The Economist journal delivered the following viewpoint on its traditional page Economics Focus: real options will be able to obtain a wide circulation in practice unless and until most managers hold a doctorate in applied mathematics. However, due to exactly real options, many leading global companies managed to be greatly in advance of their competitors in business significantly increasing their market capitalization. Perhaps, the most shining example of this includes Amazon.com that was in due time even called "a cold table of real options (Roche, 2005)".

To our opinion, a reasonable understanding of this problem should imply a progressive perception of true requirements and missions of economics in general and business in particular. Thus, for instance, already for a long time, instruments used by businessmen and financial analysts in their work include computer resources support, which greatly accelerates processes of taking managerial decisions. For example, building a simple linear regression for predicting any economic indicators can be now done almost in any software program, including in $M S$ Excel. Another example of this includes the use in financial calculations of linear and integer programming that is necessary for certain investment missions. Nevertheless, the theory of these methods itself implies deep studies in applied mathematics. 
For real options, there are also appropriate software packages enabling quite easily to enter basic data into a program and quickly obtain a final result in the form of an eventual figure meaning, for example, the real option value, which then may be, for instance, added to NPV of an investment project. Such procedure already makes no businessman or analyst feel uneasy since it is elementary. However, the use of real options in practice of doing business should not be satisfied by this. To our opinion, there are two reasons for that. 1) Many scientists, such as Roche (2005), fairly believe that real options are associated with many purely technical problems of financial nature, which should be primarily attributed to the fact that a considerable number of companies prefer to have real options at their disposal, but not to exercise them at the same time. This leads to unjustified overvaluation of investment and innovation projects that may in reality turn out to be even unprofitable. This adversely affects future marketable value of such a company. 2) The principle of real option building and analysis itself should focus its attention primarily on placing financial tasks, because incorrectly formulated investor's objectives will clearly lead to erroneous and, therefore, ineffective management decisions. A correct understanding by an investor of what it wants to get out of business is much more important than the mathematical methods themselves for the solution of standard tasks in many ways. Simply put, a correct statement of a problem is already a half-solved problem.

Taking into account the above reasons will contribute to moving the primary focus onto a more adequate building of the real option in order to solve tasks of corporate innovative development. And only after that, it will be possible to select the most optimal method of valuating the option. One of the most rational approaches for building and applying real options, according to our reckoning, includes their perception not as European options using the Black Scholes model (Black \& Scholes, 1973) for solving, and not as American options using a classical binomial model for calculations, but understanding of a real option as an Asian option, i.e. an option with a variable strike price. In the work by Trifonov, Yashin and Koshelev (2014) we bore it in mind by dint of ination pressure, the problem is far from being satisfied only by this. The reality of using real options in business consists in the fact that an option seller (customer) like an option buyer (investor) also relies on business exibility and, therefore, calculates it too. Consequently, there is a bilateral exibility for two legal entities of an option contract.

In connection therewith, it is not quite understandable why some critics of the real option valuation theory (ROV) require definition of the term `real option'. Currently, there is much the same situation in solving this problem as, for example, in attempts to determine atoms and molecules in like manner, or, perhaps, physics and mathematics. Real options have become an integral part of any investment analysis, so they are used, for instance, to handle the task of equipment replacement in companies. (Not to speak of the cost of reputation and qualification of top managers, the cost of brands, etc.). The fact is that real options are already two widely different self-developing trends: 1) ROV as legal contracts; 2) ROV as a method of financial estimate of almost everything in business.

Determining the cost of a project with its real options is particularly attributed to the selection of an adequate evaluation model. The principal models used in business are the following. 1) Black-Scholes model (Black \& Scholes, 1973). Some authors believe that this model is not applicable for estimating the cost of a real option (Trifonov, Yashin, \& Koshelev, 
2011). Other authors are of the opinion that it can be still used to obtain a pessimistic valuation of a real option (Limitovsky, 2004). 2) Binomial model (Cox, Ross, \& Rubinstein, 1979). Although this model is more simple to calculate and more adapted for valuation of real options in particular (Bastian-Pinto, Brandao \& Ozorio, 2012; Copeland \& Antikarov, 2001; Hull, 2006; Jabbour, Kramin \& Young, 2001; Mun, 2002; Trigeorgis, 1996), it includes a strong uncertainty factor originating from the fact that it has a binary decision tree containing only two option cost variation branches between nodes of the binomial lattice (Haahtela, 2010). 3) Trinomial model (Boyle, 1988; Derman, Kani \& Chriss, 1996; Haahtela, 2010; Hull, 2006; Tian, 1993). In this model, the trinomial decision tree contains three branches between nodes of the trinomial lattice, which minimizes the uncertainty and, where applicable, miscalculation of the option cost (Derman, Kani \& Chriss, 1996; Hull, 2006; Haahtela, 2010; Tian, 1993). And while this model is more accurate, there is another even more accurate diffusion model. 4) Geometric Brownian motion model (Camara, 2002; Haahtela, 2006; Rubinstein, 1983). This is based on the solution of respective differential equations. However, despite its high computational accuracy, it can scarcely ever meet the challenge of estimating the cost of compound real options.

But one should remember that in this connection, volatility estimation is often the most difficult problem in valuation of an option. This tosses a new challenge to the real options theory as the underlying asset of a known process is not always processable, and volatility does not remain permanent throughout the duration of an investment period. Volatility tends to decrease during implementing many investment projects, while new information and knowledge are collected. The evaluation method used should also consider this. On the other hand, the practical evaluation method should also be sound and intuitively attractive. Haahtela (2010) developed a recombining trinomial lattice with a view to applying the variable volatility real option valuation method (ROV). The trinomial tree implies both its direct parameterization and application of the lattice method in order to evaluate investments with several interworking parallel and sequential real options.

Unlike financial options, the market weight of assets underlying the option value is by no means always known in ROV at the beginning, which rather resembles evaluation with uncertainty. This is an uncertainty of the second order, or ambiguity, and this means that the basic value of the assets is not known at the beginning. Then, after collecting market information and following own activities for a long time, more reliable assessments of the expected value of investments and its volatility may be made. As a result, volatility tends to decrease with the course of time in many investment projects. For example, knowing sales of a product for an earlier period of time will probably improve predictive estimates of the overall demand.

A great many of project initiatives (scientific insights, complete expansion, start-up of new services, etc.) are multiple-stage investments into a project where top managers can decide to expand, curtail, uphold the status or abandon the project following receipt of new information to resolve the problem of uncertainty. For example, an investment project divided into several phases, including authorization, design, development and construction, may be either completed or continued in the following phase depending on the market condition at the close of each phase. These are compound options where exercising one option confers a right to another option, thus making the value of one option dependent on the value of another option. 
A compound option obtains its destination for another option - not from the basic asset. First investments create a right, other than an obligation, to make second investments, which, in turn, entitle to make third investments and so forth. It is always possible to decide to abandon, curtail or expand the project at any time during its implementation (Kodukula \& Papudesu, 2006).

Compound real options may be of two types: 1) Options, at the heart of which there are a few basic assets, i.e. projects or project development scenarios (Chance, 2001; Copeland \& Antikarov, 2001; Hull, 2006; Limitovsky, 2004; Mun, 2002; Smith \& Trigeorgis, 2004). 2) Options, at the heart of which there are other options acting as basic assets. In economics literature, such a situation is called an option on option (Chance, 2001; Copeland \& Antikarov, 2001; Hull, 2006; Limitovsky, 2004; Mun, 2002; Smith \& Trigeorgis, 2004). Such structures include parallel and sequential options. Parallel options exist at the same point of time but on different assets. For instance, this is a company buyout using the LBO (leveraged buyout) scheme. When analyzing a parallel compound option, the value of one option is contingent on the value of another option. For example, a pharmaceutical company currently sailing through a certain process of drug approval by the FDA must go through human trials. A successful approval by the FDA is significantly dependent on the successful human trials that happen together (Mun, 2002). Sequential options are options whose existence condition includes future options entitling to exercise current options. For example, this may include a phased execution of a project where each phase is an option on a future option, i.e. a phase (Limitovsky, 2004).

A real option that can exist in this case is something of a compound option to expand. For instance, a company can expand its offers for products and services by branching out into ancillary technologies or various applications, or into sundry markets. However, these expansions will be sure to occur in a phased manner, and moving from one phase to another relies heavily on the success of the previous phases (Mun, 2002).

In the business practice, the use of the structures of the $2^{\text {nd }}$ type, i.e. "option on option", is more complicated than the structures of the $1^{\text {st }}$ type. Furthermore, they are necessary not in every instance. There are many projects that are implemented in a single phase, even though it implies many alternatives of project development. In addition, in order to build up more complicated option structures, it is first necessary to learn to analyze their elementary alternatives.

\section{Exposition of the Model and Main Results}

\section{Model Setup}

In this research, we are going to evaluate compound real options of the $1^{\text {st }}$ type, i.e. those whose basic assets include various projects and their development scenarios. The technical structure of such compound real options consists in supplementing project evaluation that has been already conducted using the net present value (NPV) with a number of real options including the following Table 1. 
Table 1

Main Types of Compound Real Options

\begin{tabular}{|l|l|}
\hline Name & Examples \\
\hline $\begin{array}{l}\text { 1. Option to scale down a business } \\
\text { (put option) }\end{array}$ & Change-over to equipment derated operation \\
\hline $\begin{array}{l}\text { 2. Option to abandon a business } \\
\text { (put option) }\end{array}$ & Business for sale at a knockdown price \\
\hline $\begin{array}{l}\text { 3. Option to develop a business } \\
\text { (call option) }\end{array}$ & $\begin{array}{l}\text { Possibility of business build-up, acquisition of spare business } \\
\text { opportunities, scientific insights and R\&D, reservation }\end{array}$ \\
\hline $\begin{array}{l}\text { 4. Option to expand an experience } \\
\text { (call option) }\end{array}$ & Use of project experience at other facilities \\
\hline $\begin{array}{l}\text { 5. Option to switch over a business } \\
\text { (call option) }\end{array}$ & Realignment of equipment to an allied production \\
\hline $\begin{array}{l}\text { 6. Option to delay a project start } \\
\text { (call option) }\end{array}$ & $\begin{array}{l}\text { Gathering of additional project information and marketing research } \\
\text { until the time when a decision to start the project is made }\end{array}$ \\
\hline
\end{tabular}

Projects with compound real options are evaluated according to the following algorithm. 1. Building a binary decision tree for the project base-case scenario (Figure 1).

For that end, Figure 1 uses the following designations:

Year:

$\mathbf{O}$ 1

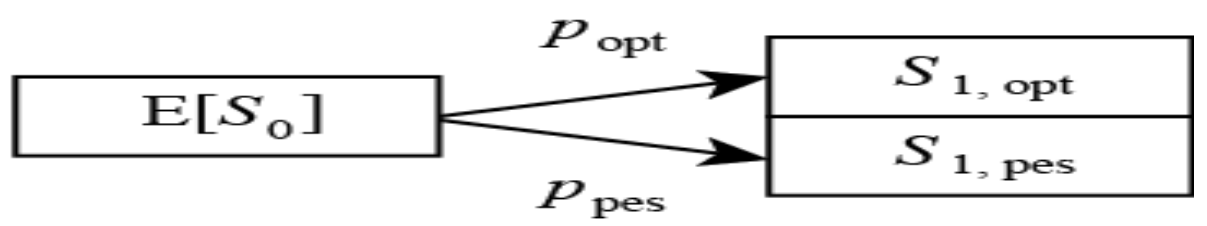

NPV: $\quad E\left[S_{0}\right]-K$

Figure 1. Binary Decision Tree for the Project Base-Case Scenario

\section{Transformational Leadership and Service Quality}

$S_{1, \mathrm{opt}}$ and $S_{1, \text { pes }}$ - optimistic and pessimistic values of future cash receipts from the project adjusted to their initial conditions (RUB);

$p_{\mathrm{opt}}$ and $p_{\mathrm{pes}}$ - probabilities of the best-case and worst-case project development scenarios;

$\mathrm{E}\left[S_{0}\right]$ - expected value of future cash receipts from the project adjusted to the kick of investments into it (RUB):

$$
\mathrm{E}\left[S_{0}\right]=\frac{S_{1, \mathrm{opt}} \cdot p_{\mathrm{opt}}+S_{1, \mathrm{pes}} \cdot p_{\mathrm{pes}}}{1+\mathrm{WACC}}
$$

WACC - weighted average cost of capital of the project or the company (\%);

$K$ - investments into the project, i.e. project execution price (RUB).

1. Calculating $\mathrm{NPV}_{\text {old }}$ of the project base-case scenario, i.e. a project without any option or a project with already available options.

2. Building a new binary decision tree similar to Figure 1 for a new option on a project without any option or a project with already available options. 
3. Calculating $\mathrm{NPV}_{\text {new }}$ of the new binary decision tree.

4. Calculating a premium for a call $\left(\Delta_{0}\right)$ or put ( $\left.\Delta P_{0}\right)$ option according to the formulas:

$$
\Delta C_{0}=\mathrm{NPV}_{\text {new }}-\mathrm{NPV}_{\text {old }} \text { or } \Delta P_{0}=\mathrm{NPV}_{\text {new }}-\mathrm{NPV}_{\text {old }}
$$

The algorithm of that kind is repeated a good many times until all the strategic project (business) development possibilities have been considered using real call and put options. The full range of such possibilities specifically represents a compound real option. In this context, call options entitle to obtain some new strategic outlooks (projects or their alternatives), and put options confer a right to the dissolution of some business lines (projects or their alternatives).

A classic example of a real call option inspired by the strategic outlooks of a company business includes an option to expand an experience. For instance, a company plans to create a chain of restaurants using a new technology in this industry. For that end, it launches a pilot project that even with a negative NPV provides new information on this business line and strategic opportunities of the new technology market. Provided that no competitor makes use of the company's experimental results, it will be entitled to launch a series of new projects, i.e. new restaurants operating according to the new technology, which may already allow for securing significant profits that will cover losses from the pilot project (Limitovsky, 2004).

An example of using a real put option may include an option to abandon a business, which a company will be able to exercise in the event of implementing the worst-case scenario. In this case, it is first required to calculate probabilities of implementing the worst-case scenario at different times of the project planning horizon. Then goes projection of the liquidation value of the business, which the company plans to abandon. Evaluation of such scenarios makes it possible to manage strategic business risks and, consequently, suffer minimum losses in case of a failure (Limitovsky, 2004; Yashin, Trifonov \& Koshelev, 2017).

\section{Results}

As an illustration of the valuation of a compound real option, let us consider a project of Stalprom LLC (Nizhny Novgorod) for organizing the manufacture of glass steel products (GRP plastic flooring and GRP plastic extrusions). The expectable cash flows under the project base-case scenario, i.e. without any option, are shown in Table 2.

Table 2

Cash Flows of a Project for Organizing Manufacture of Glass Steel Products (RUB '000)

\begin{tabular}{|c|c|c|c|c|c|}
\hline Development & \multicolumn{5}{|c|}{ Cash flows by year } \\
\cline { 2 - 6 } scenario & 0 & 1 & 2 & 3 & 4 \\
\hline Optimistic & $-5,500$ & 3,000 & 3,500 & 3,750 & 5,800 \\
Pessimistic & $-5,500$ & 120 & 480 & 790 & 900 \\
\hline
\end{tabular}

The project development scenarios are equally probable. The estimated corporate weighted average cost of capital is $\mathrm{WACC}=25 \%$ per annum. Let us first evaluate the profitability of the project base-case scenario, i.e. without options:

$$
S_{1, \mathrm{opt}}=3,000+\frac{3,500}{1.25}+\frac{3,750}{1.25^{2}}+\frac{5,800}{1.25^{3}}=11,169.6
$$




$$
\begin{gathered}
S_{1, \mathrm{pes}}=120+\frac{480}{1.25}+\frac{790}{1.25^{2}}+\frac{900}{1.25^{3}}=1,470.4 \quad\left(\mathrm{RUB}{ }^{\prime} 000\right) \\
\left.\mathrm{E}\left[S_{0}\right]=\frac{11,169.6 \cdot 0.5+1,470.4 \cdot 0.5}{1.25}=5,056 \quad(\mathrm{RUB})^{\prime} 000\right) \\
\left.\mathrm{NPV}=5,056-5,500=-444(\mathrm{RUB})^{\prime} 000\right)
\end{gathered}
$$

The binary decision tree is shown in Figure 2.

Year:

$\mathbf{O}$

1

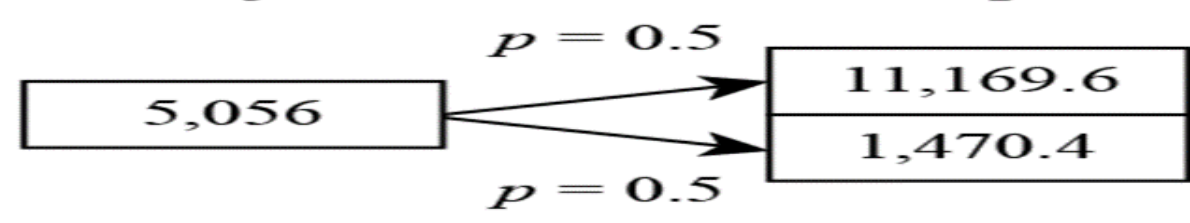

NPV:

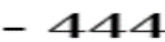

Figure 2. Binary decision tree for the project base-case scenario (without options)

The NPV of the project base-case scenario is negative, so the project is unprofitable. However, in order to evaluate it more accurately, it is required to take into account strategic opportunities, which it will provide in future. For this purpose, we are going to use a compound real option whose components are described in Table 1.

1. Option to scale down a business. While implementing the worst-case scenario, the company may put the equipment involved in the project on a simplified operating mode. It seems clear that in the example in question, this is unprofitable since already small cash inflows of the project will decline on top of everything else. However, the outcome might be different if the worst-case scenario would contemplate not cash inflows starting from the first year but losses of the same amount in absolute value as in Table 2.

We assume that the change-over to the equipment derated operation will reduce cash flows by $30 \%$. Additional investments and imputed costs under such conditions will be 115,000 rubles. In the optimistic case, there is no point in doing that. We calculate below how it is possible to cut down the present value of losses in the worst-case scenario:

$$
S_{1, \mathrm{pes}}=-120+(-1,470.4+120)(1-0.3)-115=-1,180.28 \text { (RUB '000) }
$$

The new binary decision tree is shown in Figure 3. In Figure 3, calculations were carried out as follows:

$$
\begin{gathered}
\mathrm{E}\left[S_{0}\right]=\frac{11,169.6 \cdot 0,5-1,180.28 \cdot 0.5}{1.25}=3,995.73\left(\mathrm{RUB}^{\prime} 000\right) \\
\mathrm{NPV}_{\text {new }}=3,995.73-5,500=-1,504.27 \text { (RUB '000) }
\end{gathered}
$$


In order to evaluate, to what extent this transaction will allow to reduce losses, let us first calculate $\mathrm{NPV}_{\text {old }}$ and then a premium for the put option $\left(\Delta P_{0}\right)$ :

$$
\begin{gathered}
\mathrm{E}\left[S_{0}\right]=\frac{11,169.6 \cdot 0.5-1,470.4 \cdot 0.5}{1.25}=3,879.68\left(\mathrm{RUB}{ }^{\prime} 000\right) \\
\mathrm{NPV}_{\text {old }}=3,879.68-5,500=-1,620.32\left(\mathrm{RUB}^{\prime} 000\right) \\
\Delta P_{0}=\mathrm{NPV}_{\text {new }}-\mathrm{NPV}_{\text {old }}=-1,504.27+1,620.32=116.05\left(\mathrm{RUB}^{\prime} 000\right)
\end{gathered}
$$

As can be seen from the above calculations, the change-over to the equipment derated operation will allow to reduce the present value of potential losses by 116.05 rubles. Although in the example in question the worst-case scenario contemplates not losses but cash flows starting from the first year, in other examples, i.e. projects, accounting for this option to scale down the business may become a precondition for the formation of a sufficiently complete compound real option on the base project.

\section{Year:}

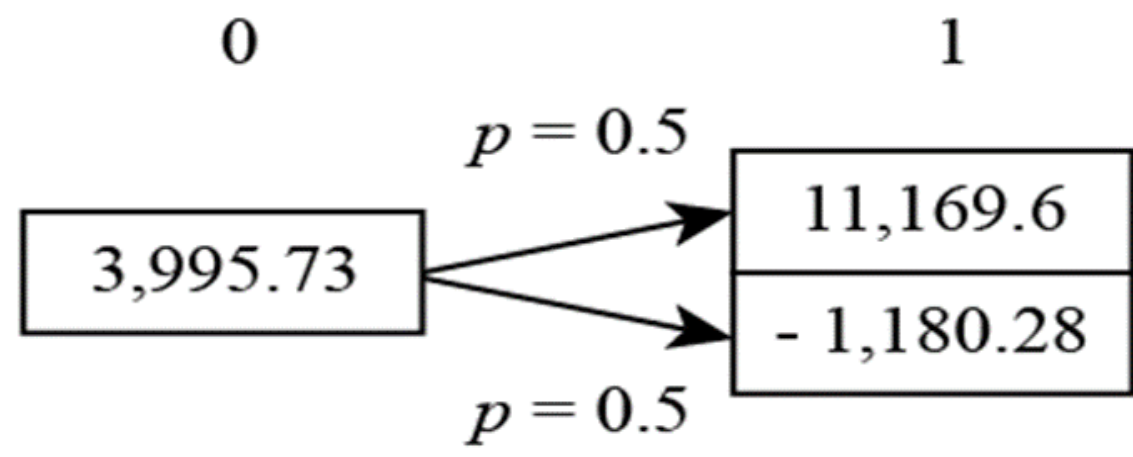

NPV:

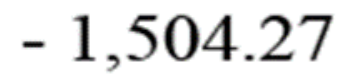

Figure 3. Binary Decision Tree for a Project with an Option to Scale down a Business

2. Option to abandon a business. The expected net benefit from the project dissolution in the first year will be 1,750,000 rubles. This transaction only makes sense in the pessimistic case, then

$$
S_{1, \mathrm{pes}}=120+1,750=1,870 \text { (RUB '000) }
$$

The new binary decision tree is constructed in Figure 4. As can be seen from Figure 4, the specified strategic opportunity significantly reduced the negative effect of the project to -284.16 thousand rubles. Premium for the put option to abandon the business:

$$
\Delta P_{0}=-284.16+444=159.84\left(\mathrm{RUB}{ }^{\prime} 000\right)
$$


Year:

NPV:
$\mathbf{O}$

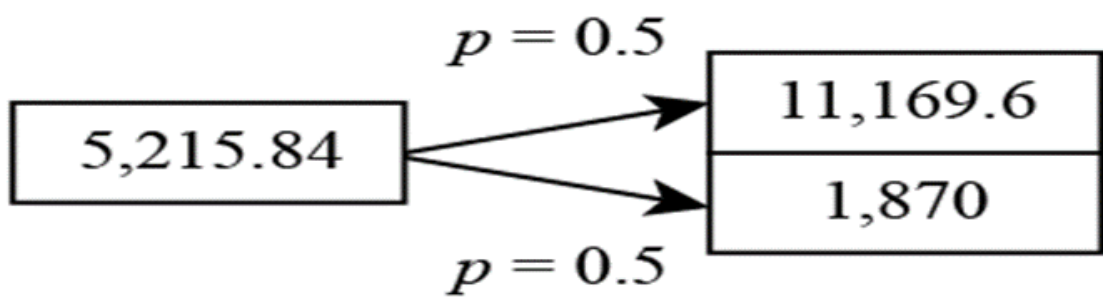

Figure 4. Binary decision tree for a project with an option to abandon a business

3. Option to develop a business. Based on the results of the first year, it is possible to purchase, deliver and install a waste disposal plant to arrange for the new non-waste technology production. For that end, it is required to invest in the project another 1,500,000 rubles. In this case, the project cash flows will increase by $30 \%$. The result of the best-case scenario will then change:

$S_{1, \mathrm{opt}}=3,000+(11,169.6-3,000)(1+0.3)-1,500=12,120.48$ (RUB '000).

The new binary decision tree is constructed in Figure 5. As can be seen from Figure 5, the NPV of the project with the new option became positive. Premium for the call option to develop the business:

$$
\Delta C_{0}=96.19+284.16=380.35 \text { (RUB '000). }
$$

Year:

$\mathbf{O}$ 1

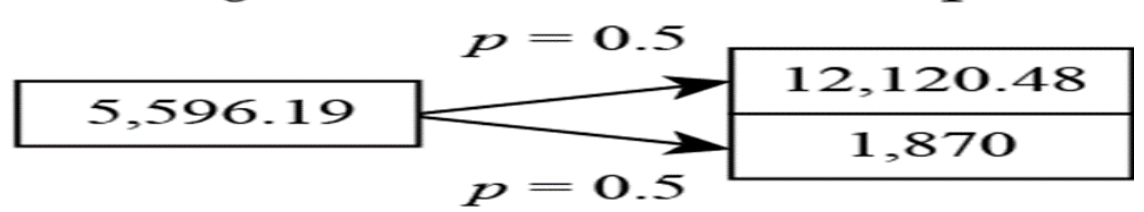

NPV:

96.19

Figure 5. Binary decision tree for a project with an option to develop a business

4. Option to expand an experience. If optimistic expectations are implemented in the next year, it will be possible to replicate the project once on another site. The overall investments into the new replicated project will be

$$
I=5,500+1,500=7,000(\text { RUB '000). }
$$

Since this decision will be supposedly taken no sooner than a year after, the NPV of the new second replicated project at the end of the first year will be

$$
\mathrm{NPV}_{1}^{(2)}=\frac{12,120.48}{1.25}-7,000=2,696.38 \quad\left(\mathrm{RUB}{ }^{\prime} 000\right)
$$

This transaction will be only made in the optimistic case, then given the old first project 


$$
S_{1, \mathrm{opt}}=12,120.48+2,696.38=14,816.86 \text { (RUB '000). }
$$

The new binary decision tree is shown in Figure 6.

Year:

$\mathbf{O}$

1

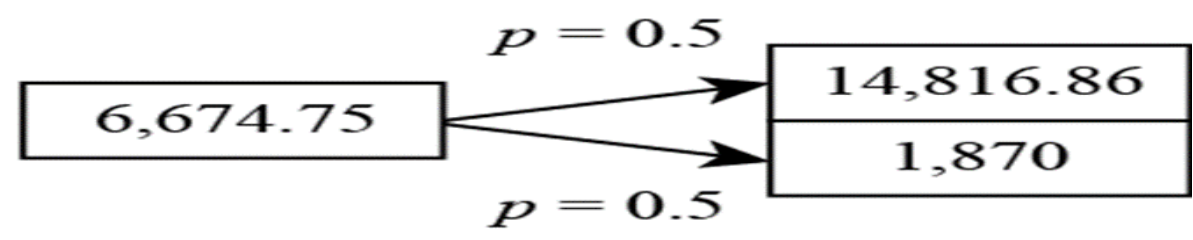

NPV:

$1,174.75$

Figure 6. Binary decision tree for a project with an option to expand an experience

The NPV of the project providing for its replication in one instance became much greater, which is indicative of the profitability of this transaction. The premium for the call option to expand the experience is also significant:

$$
\Delta C_{0}=1,174.75-96.19=1,078.56\left(\mathrm{RUB}{ }^{\prime} 000\right)
$$

6. Option to switch over a business. The product market forecast is not reliable enough. However, if the worst expectations are confirmed, there is a possibility to repurpose the project equipment to an allied production. Potential wholesale buyers of allied products are wellknown. The value of cash inflows adjusted as of the end of the first year for this new technology $Y$ taking into account all the previously composed options in the best-case scenario will be equal to $S_{1, \text { opt }}=12,500$ thousand rubles and in the worst-case scenario $-S_{1, \text { pes }}=2,700$ thousand rubles. That said, switching over from the old technology $X$ to the new technology $Y$ requires additional capital investments amounting to 800,000 rubles. In this case, it is required to allow for the both scenarios: optimistic and pessimistic:

$$
S_{1, \mathrm{opt}}=3,000+12,500-800=14,700<14,816.86 \text { (RUB '000) }
$$

$\Rightarrow$ there is no point in switching over to the new technology $Y$;

$$
S_{1, \mathrm{pes}}=120+2,700-800=2,020>1,870 \text { (RUB '000) }
$$

$\Rightarrow$ switching over to the technology $Y$.

The new binary decision tree is shown in Figure 7. 
Year:

$\mathbf{O}$

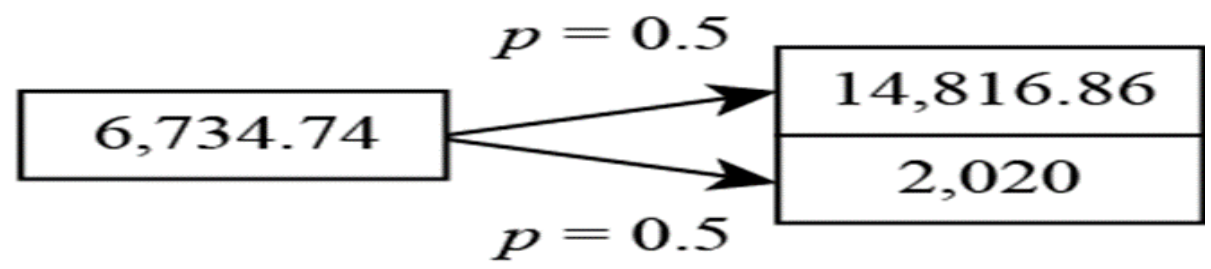

NPV:

$1,234.74$

Figure 7. Binary decision tree for a project with an option to switch over a business

The NPV of the project with the new option became still greater. Premium for the call option to switch over the business:

$$
\Delta C_{0}=1,234.74-1,174.75=59.99 \text { (RUB '000). }
$$

7. Option to delay a project start. The factory has another year at hand to think over and decide upon whether to start the project. During the year, it is possible to conduct marketing research priced at 750,000 rubles.

Let us start the project in the best-case scenario, then according to estimates as of the end of the first year

$$
\mathrm{NPV}_{\mathrm{opt}, 1}=\frac{14,816.86}{1.25}-5,500=6,353.49 \text { (RUB '000). }
$$

The binary tree of the option value is shown in Figure 8. The adjusted present value (APV) in year 0 , i.e. at the time of evaluation of the project with all the options taking into account the marketing costs, will be

$$
\mathrm{APV}=2,541.4-750=1,791.4\left(\mathrm{RUB}{ }^{\prime} 000\right)
$$

and the premium for the call option to delay the project start -

$$
\Delta C_{0}=1,791.4-1,234.74=556.66 \text { (RUB '000). }
$$

Year:

$\mathbf{O}$

1

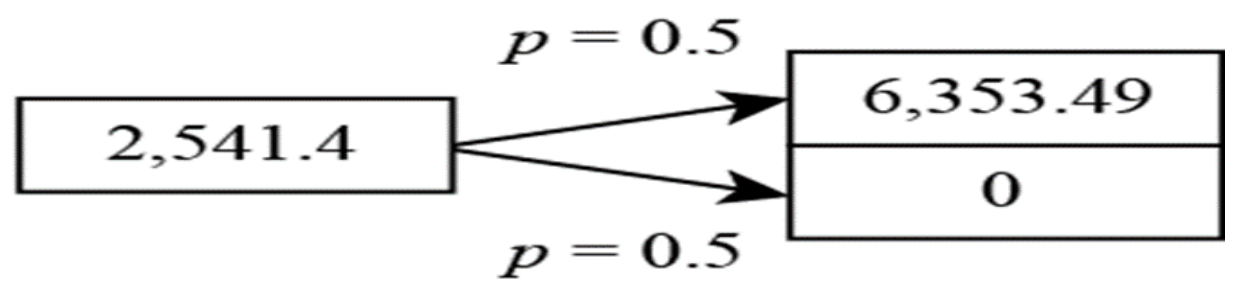

Figure 8. Binary tree of the value of an option to delay a project start.

\section{Discussion}

The final conclusion for this example will include the fact that the APV of Stalprom's project for organizing the manufacture of glass steel products providing for any possible strategic 
project development outlook, i.e. in view of the compound real option, is estimated as 1,791,400 rubles. It is to be recalled that with no regard for the compound option, the project effect, i.e. NPV, was estimated as -444 thousand rubles.

It is also important to construct a compound real option correctly, i.e. to build it up exactly in the sequence as described in this example. Such sequence of planning a compound option is inspired by the logic itself for planning a business and production in particular. In other words, it is first necessary to evaluate potential negative project development scenarios using applicable put options, then - strategic outlooks of the project capacity building using call options. Otherwise, it makes no sense to plan any business scaling down or abandonment if all possible positive prospects for the development of the resulting project complex were taken into account before that.

\section{Conclusion}

Finally, following conclusions were drawn based on the research findings:

1. In the business practice, the full range of strategic business development outlooks related to a specific innovation project shall be evaluated.

2. Determining the cost of a project with its real options is particularly attributed to the selection of an adequate evaluation model. However, even despite the high computational accuracy of a particular model, it can scarcely ever meet the challenge of estimating the cost of compound real options.

3. Compound real options may be of two types: 1) options, at the heart of which there are a few basic assets, i.e. projects or project development scenarios; 2) options, at the heart of which there are other options acting as basic assets (options on options).

4. This research presents a model for evaluating compound real options of the first type, i.e. those whose basic assets include various projects and their development scenarios. The technical structure of such compound real options consists in supplementing project evaluation that has been already conducted using the net present value with a number of real options, such as an option to scale down a business, an option to abandon a business, an option to develop a business, an option to expand an experience, an option to switch over a business, and an option to delay a project start.

5. As an illustration of the valuation of a compound real option, a project of Stalprom LLC (Nizhny Novgorod) for organizing the manufacture of glass steel products (GRP plastic flooring and GRP plastic extrusions) is described. It is found that the adjusted present value (APV) of this project inclusive of any possible strategic outlook of its development, i.e. in view of the compound real option, is equal to 1,791,400 rubles. With no regard for the compound option, the project effect, i.e. NPV, is equal to -444 thousand rubles.

6. It is important to construct a compound real option correctly, i.e. to build it up exactly in the sequence as described in paragraph 4 of these conclusions. Such sequence of planning a compound option is inspired by the logic itself for planning a business and production in particular. In other words, it is first necessary to evaluate potential negative project development scenarios using applicable put options, then - strategic outlooks of the project capacity building using call options. Otherwise, it makes no sense to plan any business scaling down or abandonment if all possible positive prospects for the development of the resulting project complex were taken into account before that. 
The results of this research may be useful to financial analysts of manufacturing companies and to their top managers to make adequate decisions in regards to the efficiency of investment and innovation projects.

\section{Acknowledgment}

This research has been performed with financial support from the Russian Foundation for Basic Research within the confines of scientific project No. 19-010-00932 "Creating an innovation system development model for industrial regions under current conditions of social and economic development".

\section{References}

Bastian-Pinto, C. L., Brandao, L. E. T., \& Ozorio, L. M. (2012). A symmetrical binomial lattice approach, for modeling generic one factor Markov processes. Paper presented at the 16th Annual International Conference of Real Options: Theory Meets Practice, Great Britain, London. Abstract retrieved from http://realoptions.org/openconf2012/data/papers/26.pdf

Black, F., \& Scholes, M. (1973). The pricing of options and corporate liabilities. Journal of political economy, 81(3), 637-654.

Boyle, P. (1988). A lattice framework for option pricing with two state variables. Journal of Financial and Quantitative Analysis, 23, 1-12.

Camara, A. (2002). The valuation of options on multiple operating cash flows. Paper presented at the 6th Annual International Conference of Real Options: Theory Meets Practice, Cyprus, Paphos. Abstract retrieved from http://www.realoptions.org/papers2002/Camarajbf-p.pdf

Chance, D.M. (2001). Introduction to derivatives and risk management (6th ed.). Fort Worth, TX: Harcount College Publishers.

Copeland, T., \& Antikarov, V. (2001). Real options: A practitioner's guide. New York: TEXERE.

Cox, J., Ross, S., \& Rubinstein, M. (1979). Option pricing: A simplified approach. Journal of Financial Economics, 7, $229-263$.

Damodaran, A. (2002). Investment valuation: Tools and techniques for determining the value of any asset. New York: John Wiley $\&$ Sons, Inc.

Derman, E., Kani, I., \& Chriss, N. (1996). Implied trinomial trees of the volatility smile. The Journal of Derivatives Summer, 3(4), 7-22.

Haahtela, T. (2006). Extended binomial tree valuation when the underlying asset distribution is shifted lognormal with higher moments. Paper presented at the 10th Annual International Conference of Real Options: Theory Meets Practice, USA, New York. Abstract retrieved from http://www.realoptions.org/abstracts_2006.html

Haahtela, T. (2010). Recombining trinomial tree for real option valuation with changing volatility. Paper presented at the 14th Annual International Conference of Real Options: Theory Meets Practice, Italy, Rome. Abstract retrieved from http://www.realoptions.org/papers2010/241.pdf

Hull, J. (2006). Options, futures and other derivatives (6th ed.). Upper Saddle River, New Jersey: Pearson Education, Inc.

Jabbour, G., Kramin M., \& Young S. (2001). Two-state option pricing: Binomial models revisited. Journal of Futures Markets, $21,987-1001$

Kodukula, P., \& Papudesu, Ch. (2006). Project valuation using real options: A practitioner's guide. USA, Florida, Fort Lauderdale: J. Ross Publishing, Inc.

Limitovsky, M.A. (2004). Investment projects and real options in emerging markets. Moscow: Urait.

Mun, J. (2002). Real options analysis: Tools and techniques for valuing strategic investments and decisions. USA, New Jersey: John Wiley \& Sons.

Roche, J. (2005). The value of nothing: Mastering business valuations. London: Lessons (Publishing) Limited.

Rubinstein, M. (1983). Displaced diffusion option pricing. Journal of Finance, 38(1), 213-217.

Smith, H. T. J., \& Trigeorgis, L. (2004). Strategic investment: Real options and games. Princeton and Oxford: Princeton University Press.

Tian, Y. (1993). A modified lattice approach to option pricing. The Journal of Futures Markets, 13(5), 563-577.

Trigeorgis, L. (1996). Real options: Managerial flexibility and strategy in resource allocation. Cambridge, Mass: MIT Press.

Trifonov, Yu. V., Yashin, S. N., \& Koshelev, E. V. (2011). Using real options for innovation investments under information limitation conditions. Finance and Credit, 30(462), 2-9. 
Trifonov, Yu., Yashin, S., \& Koshelev, E. (2014). Stock market technologies in business. Working Paper. Social Science Research Network, November, 7, 2014. http://ssrn.com/abstract=2519621

Yashin, S. N., Trifonov, Yu. V., \& Koshelev, E. V. (2017). Creating a mechanism for managing innovative development of an industrial region. Nizhny Novgorod: Radonezh Printing Shop LLC. 